\title{
Accountability in medical education from theory to practice Tabriz 2018 statement: A step towards the implementation of this social necessity
}

\author{
Reza Ghaffari', Ali Taghizadieh², Mozhgan Behshid*1,3 (D), Mohammad Husein Somi ${ }^{4}$, Azim Mirzazadeh ${ }^{5}$, \\ Hamid Reza Baradaran ${ }^{6}$, Mark Huntington ${ }^{7}$, Seyed Hasan Emami Razavi ${ }^{8}$, Flora Baghban Rezvan ${ }^{1}$, \\ Fariba Salek Ranjbarzadeh ${ }^{1}$
}

Received: 16 Jul 2019

Published: 6 Aug 2020

\section{Abstract}

Background: To implement the education reform package on accountability in medical education, the Education Development Center (EDC) of Tabriz University of Medical Sciences has held the first national conference on accountability in medical education, and the present statement is the result of scientific interactions and exchanges in the conference.

Methods: For implementation of the accountability in medical education, there was a need to inform faculty members and other stakeholders about their responsibility in education and health care needs. The provision of such platform was provided by holding a specialized conference on accountability in medical education by Tabriz University of Medical Sciences. Steps of preparing the draft version of the Tabriz 2018 Statement were as follow: Formation the scientific committee; Division of the responsibility for drafting the statement between various workgroups; and Preparation and primary approval of the draft of Tabriz 2018 Statement.

Results: Steps of preparing the draft version of the Tabriz 2018 Statement were: Formation of the scientific committee, Division of the responsibility for drafting the statement between the various workgroups and Preparation and primary approval of the draft of Tabriz 2018 Statement

Conclusion: Establishing an educational accreditation model and reviewing accreditation standards based on social accountability can be an effective step to strengthen accountability towards community needs.

Keywords: Accountability, Medical, Education, Implementation

Conflicts of Interest: None declared

Funding: None

\section{*This work has been published under CC BY-NC-SA 1.0 license.}

Copyright $\odot$ Iran University of Medical Sciences

Cite this article as: Ghaffari R, Taghizadieh A, Behshid M, Somi MH, Mirzazadeh A, Baradaran HR, Huntington M, Emami Razavi SH, Baghban Rezvan F, Salek Ranjbarzadeh F. Accountability in medical education from theory to practice Tabriz 2018 statement: A step towards the implementation of this social necessity. Med J Islam Repub Iran. 2020 (6 Aug);34:93. https://doi.org/10.47176/mjiri.34.93

\section{Introduction}

Discovering new disease mechanisms, creating new treatments, and designing better ways to provide care are

\section{Corresponding author: Dr Mozhgan Behshid, behshidm@tbzmed.ac.ir}

1. Medical Education Research Center, Health Management and Safety Promotion Research Institute, Tabriz University of Medical Sciences, Tabriz, Iran

2. Tuberculosis and Lung Research Center, Tabriz University of Medical Sciences, Tabriz, Iran

3. Faculty of Nursing and Midwifery, Tabriz University of Medical Sciences, Tabriz, Iran

4. Liver and Gastrointestinal Diseases Research Center, Tabriz University of Medical Sciences, Tabriz, Iran

5. Department of Medical Education, Tehran University of Medical Sciences, Tehran, Iran

6. Endocrine Research Center, Institute of Endocrinology and Metabolism, Iran University of Medical Sciences, Tehran, Iran

7. Department of Family Medicine, School of Medicine, University of South Dakota Sanford, 414 E. Clark Street, Vermillion, SD 57069, United States

8. Neuroscience Institute, Brain and Spinal Cord Injury Research Center (BASIR), Tehran University of Medical Sciences, Tehran, Iran necessary to promote health, but not enough. Ensuring adequate health through optimal clinical education is essential to fill the gap between the current health outcomes and the expected outlook (1).

$\uparrow$ What is "already known" in this topic:

There is no national-level study on the implementation of accountable medical education and the studies have been either academic or conducted at regional level.

\section{$\rightarrow$ What this article adds:}

Reaching a common language on the concepts, domains, and indicators of indigenous responsive medical education, and preparing and approving a roadmap in the form of a statement for its operationalization to respond to medical education in the country. This was done Through the organizing a focused discussion group and expert panels with the participation of all experts. 
Discussions about social accountability require responding to the society about services that the system has been set up to provide. In the health area, social accountability involves a commitment to better respond to the health needs of the citizens and society. An educational institution should examine the impact of social accountability through adherence to basic principles of quality, equity, communication, and effectiveness, and also active participation in the development of health systems. Social accountability should be measured in 3 areas involving health personnel, ie, conceptualization, production, and usability. An educational institution fully in charge of the position of a responsible partner in the health care system and committed to the public interest seeks a prominent advantage (2).

Accountability is one of the main goals of the health system and of great importance among policymakers and planners of all organizations, especially the health system. Therefore, health policymakers are seeking measures to make the system more accountable to patients and the community (3). WHO defines accountability as a commitment in guiding education, research, and medical services in line with the priorities of community, region and world health needs, based on the values of quality, equity, and cost- effectiveness. Hence, the role of universities of medical sciences regarding accountability of education, research, and medical services is evident (4). It appears that universities, through proper attention to medical science education and efforts to establish an accountable educational system, can help to realize the goals of the health system in its accountability.

The teaching of medical and health sciences takes place in laboratories and hospitals of big cities where advanced and costly technology is used, away from most of the community; educational content is also modeled from advanced countries. Accountable and community-based education is an educational executive program that takes place in the context of the community and outside of the third-level facilities. In this program, students will get familiarized with various ways of dealing with problems in the society and gain the required knowledge and skills about what they will deal with as their future career requirements. Accountable education indicates a curriculum that is based on understanding and responding to community health needs and preparing students for work and provision services to the community. Accountability in medical education focuses on every component of areas of operation, needs, and health care problems of the country, and educates physicians that have the will and ability to serve the community by dealing with health problems effectively at the 3 levels of service provision (5).

A review of studies in Iran reveals many weaknesses and challenges in accountability in medical education. Yamani et al (2013) in their study entitled "Social Accountability of Medical Education Curriculum: Barriers and Implications" found 8 major obstacles in this field: (1) mission of universities, (2) preservation of scientific autonomy of universities, (3) overcoming the quantitative paradigm (over the qualitative paradigm), (4) curriculum structure, (5) interdisciplinary interactions, (6) mismatching of curriculum content with the needs of society, (7) lack of selective courses, and (8) the collaboration between the university and the community. To address these obstacles, Yamani has provided solutions such as curriculum for developing clear missions, adding community-based education to different levels of the medical curriculum, not leaving physicians to themselves after graduation, and developing an appropriate model and theoretical framework for responding to the curriculum; and they eventually focused on moving towards the development of operational strategies (6).

Dehghani et al in a study entitled "Situation analysis of social accountability medical education in university of medical sciences and innovative point of view of clinical faculty members towards its promotion using Strengths, Weaknesses, Opportunities, and Threats (SWOT) analysis model", assessed the status accountable medical education strategies in the weakness-threat (WT) zone, which is not a good position for such education. They also assessed the relationship between the innovative activities of the faculty members and the opportunities of accountability in education as weak and the monitoring of the research and development centers of medical education on the implementation procedure of accountable education at universities as a strong point (5).

To implement the education reform package on accountability in medical education, considering that this education has found its true status in Iran and is facing many challenges and shortcomings, the Education Development Center (EDC) of Tabriz University of Medical Sciences has held the first national conference on accountability in Medical Education, and the present statement is the result of scientific interactions and exchanges in the conference.

To implement accountability in medical education, there was a need to inform faculty members and other stakeholders about their responsibility in education and health care needs. Such platform was provided by holding a specialized conference on accountability in medical education by Tabriz University of Medical Sciences.

\section{Steps of preparing the draft version of the Tabriz}

\section{Statement}

\section{Formation of the scientific committee}

The first stage of drafting the version of the accountability in medical education statement was formed by the scientific committee consisting of the authorities of education reform package on accountability in medical education in the Ministry of Health and Medical Education, preparatory and medical sciences university zones in Iran, experts in medical education, educational deputies of the universities of medical sciences of Iran, heads of medical education research and development centers, medical education researchers, and medical education professors. Team members had at least 6 months of continuous experience in the field of educational, research, and executive medical education programs; they also had a personal interest in accountable medical education activities.

One of the most important actions in this scientific committee was the creation of a common language in the field of basic concepts of medical education and accountable medical education. Moreover, the concepts of social ac- 
countability and accountable medical education were clarified.

Division of the responsibility for drafting the statement between various workgroups

To draft the statement, missions were assigned to various workgroups during the conference, including 4 panels of experts, 2 specialized meetings, 2 key lecture sessions, 4 brief lectures, 2 sessions of reviewing studies submitted as posters by the scientific committee, 9 empowerment workshops by the scientific committee, and students scientific panel as the main stakeholders, and the target group of accountability in medical education. The results of scientific discussions and executive suggestions of the sessions were summarized and presented in collection forms of innovative ideas and achievements, challenges for implementing the accountability in medical education, and suggested solutions for intervention for managing challenges at each session.

Preparation and primary approval of the draft of

\section{Tabriz 2018 Statement}

At the conclusion of various congress sessions, the proposed content was reviewed by the representatives of the scientific committee and summarized as the content of the statement draft. This was done in a special panel composed of 12 members of the scientific committee and ministry officials. Content was developed, revised, and edited clause by clause, which resulted in a statement consisting of 17 clauses.

Following the conference on accountability in medical education, to implement the education reform package on accountability in medical education, the achievements of this conference were presented in the form of a draft under the title of Tabriz 2018 Statement, consisting of 17 clauses as follows:

1. The universities of medical sciences in Iran, as trustees, should be active and accountable for identifying and meeting the health needs of the community and its determinants.

2. To provide a platform for advancing social accountability in medical education, universities of medical sciences need to address the matter not only at the individual level but also at the organizational level.

3. Community needs should be identified, and required policies and plans should also be implemented to meet the needs, while outcomes are evaluated and short- and longterm impacts of the measures are determined and ongoing review of the stages are emphasized.

4. All institutions and entities of universities of medical sciences in different functional areas should pay particular attention to social accountability and consider the core values of social accountability of education (eg, equity, accessibility, relevance, cost- effectiveness and partnership) in their strategic plan.

5. Social accountability of education should be emphasized at all disciplines and levels of education and at all levels of service, including primary, secondary, and tertiary services.
6. To complete all stages of the social accountability of education, all processes and structures of the medical education system should be reviewed accordingly and revised as necessary to improve the quality of the processes.

7. Given the unparalleled role of competency-based education in enhancing social accountability of education, educational programs should be shifted toward competencybased education at both national and academic levels in the development and revision of educational curricula. To this end, in addition to developing the capabilities of graduates, other educational program components, including educational content, methods and fields, methods of evaluating learners and faculty members, training courses, and management and educational leadership, should be reviewed to achieve the capabilities developed for the graduates.

8. Given the pivotal role of ethics and professionalism in competency-based education, as a basis for social accountability of education, special attention should be paid to the training and evaluation of ethics and professionalism in medical science educational courses.

9. Review of educational accreditation standards to enhance social accountability and full implementation of this approach in different dimensions (institutional and programmatic) in different areas of medical science education is emphasized as a key approach to quality assurance and promotion.

10. The reform of the performance evaluation system of faculty members based on the reinforcement of accountability in medical education is emphasized.

11. Emphasis is placed on strengthening need assessment methods and foresight in the curriculum planning process, and their implications shall be used for educational policymaking and planning.

12. The importance of establishing a continuous need assessment system was emphasized with the participation of all stakeholders in the field of health and community and with a multisectorial perspective.

13. The training of health personnel should be emphasized for qualitative and quantitative provision of health service providers based on evidence-based needs of the health system at all levels (primary, secondary, and tertiary) to create an equilibrium.

14. Explain the characteristics, components, and indicators of accountable education at all levels and dimensions of social accountability and pay special attention to the principles of cost-effectiveness, flexibility, and local requirements in developing indicators of accountability in medical education.

15. Innovative university research activities must meet community needs, including providing the necessary evidence to make decisions and technologies needed by the health system.

16. Grant more authority to medical universities to operate in different areas and activities of educational programs based on local needs and priorities.

17. To promote educational justice as one of the important components of accountability, medical universities shall focus on the use of modern teaching and evaluation methods, and hence access to virtual education for all learners to benefit from educational resources is emphasized. 
18. In designing and revising educational curricula, additional attention shall be paid to developing and setting educational goals in the attitudinal domain, and understanding community health needs and commitment to social, economic, and cultural accountability shall be valued.

19. Given the coverage of most of the foregoing in the Medical Education Transformation and Innovation Program, special emphasis is placed on the careful monitoring and institutionalization of transformation packages as a policy document in the field of medical education in the country.

20. Due to the necessity of following up on the activities and measures adopted for the establishment and implementation of accountability in medical education programs, it was decided that the permanent secretariat of accountability in medical education conferences will been established and started working at Tabriz University of Medical Sciences.

\section{Discussion}

Discussions about social accountability require responding to the society about measures that the system has been set up to take. In the health area, social accountability involves a commitment to better respond to the health needs of citizens and society. An educational institution should examine the impact of social accountability through adherence to the basic principles of quality, equity, communication, and effectiveness, and also active participation in the development of health system. Social accountability should be measured in 3 areas involving health personnel, ie, conceptualization, production, and usability. An educational institution fully in charge of the position of a responsible partner in the health care system and committed to the public interest seeks a prominent advantage.

Providing comprehensive evidence, communities are seeking to justify the impact of their investments on the public interest. Consequently, medical science centers also have to be prepared to be judged accordingly. Therefore, it is imperative to take swift actions to strengthen compliance with accreditation standards with norms that express social accountability. Only in this case, educational institutions can be measured and rewarded in terms of their actual capacity for meeting the comprehensive health care needs of the community.

An educational institution whose goal is to excel in the education of health care professionals must seek accountability not only in the acquisition of all the necessary capabilities to improve the health of citizens and society by their graduates, but also in the use of graduates of these capabilities in their profession (2).

The issues of social responsibility and social accountability of medical practitioners have attracted great attention. There is a growing demand for training future medical physicians with social responsibility (7). Across the world, medical schools were told that their educational, research, and service provision activities should be able to make capacity in future physicians to meet the health priorities of the community, the region and the country in which they will serve (8).

The effort to take responsibility and social responsibility is a long-term effort to describe, promote, protect, and support a social contract between the medical profession and the community. According to this agreement, medical practitioners receive special rights and privileges for the exchange of social services with general welfare (9-12). At the same time, there must be a realistic answer about the personal interests of medical practitioners $(9,13)$. Similar concerns have been observed in other health care fields. For instance, in a recent study on social responsibility in dentistry, it has been found that there is a belief among some instructors, physicians, and leaders of dentistry that economic necessities are the dominant features that shape the formation of dental education and their performance in the society (14).

Based on the findings of this research, the first step in implementing accountability in medical education is the establishment of the grounds and modification of the medical education infrastructure in accordance with the community health needs and conforming to the social determinants of health in the target community. In this regard, given the unparalleled role of medical science universities in training human resources in various medical sciences on the one hand, and the rule of the integrated system of medical education and provision of health services, on the other, these centers are recognized as the main trustees for meeting the health needs of the community and its social determinants. This role of medical science universities is first and foremost fulfilled by praising social accountability at the organizational level. Reports released from studies in this field indicate that medical science universities worldwide are tasked with planning, implementing, and evaluating their educational, research, and service provision activities in a way that can build the capacity in future medical science graduates to meet the health priorities of the community, region, and country where they will serve (10).

Another action for establishing the ground for implementation of accountability in medical education is reviewing the educational structures and processes in the field of medical sciences and praising the efforts made to improve the quality of education in line with social accountability. The continuous improvement of the quality of medical education is the focus and goal of many international medical education societies, so that Association for Medical Education in Europe (AMEE) launched the Aspire-to-excellence award program in 2012 as an innovative plan to identify the bests of medical science education in the world. Establishing the ASPIRE-to-Excellence award program, the board of the association and the selected schools of the program sought to promote the best innovative methods of medical science education and strengthen the collaboration and exchange of experiences of top universities with other universities to improve the quality of medical, dentistry, and veterinary education in the world (15). In a study of clinical learning environments, the Accreditation Council for Graduate Medical Education (ACGME) focused on improving quality to address inequalities in health care and aimed to make medical educators and residents consider the interpersonal differences in the diverse populations of patients who they serve, and focus on them in the form of designing quality improvement activities and respond to the needs of 
different population groups (16).

According to the findings of this study, social accountability in medical education requires a comprehensive look at the various levels of services, including primary, secondary, and tertiary levels, and should be considered as a necessity in all disciplines and educational levels. This issue has been the focus of many studies in this regard, and evidence suggests that social accountability at different levels of service delivery has been emphasized in educational systems of medical science practitioners in various countries $(17,18)$.

The specialized team of accountability in medical education believed that given the fact that medical school educators are the best professional role models for students, it is necessary to make changes in performance evaluation system of faculty members for the establishment of accountability in medical education, and their performance should be evaluated based on their social accountability, so that such values become a model for medical students. In their study on professional identity formation, Cruess et al (2015) acknowledged that the formation of professional identity is a dynamic process that is achieved through socialization and leads to the integration of individuals into the medical community in practice. Several factors inside and outside the educational system affect the formation of the professional identity of a person. The results of recent research on the formation of professional identity in medicine show that medical science educators are the greatest professional role models of medical students, and as one of the goals of medical education, they are responsible for supporting and directing medical students and residents to acquire their professional identity (19).

Instructors, educators, and professional role models in medical sciences can have a huge impact on the formation of students' professional identity by stimulating their attention and admiration toward their performance as a professional, and through having long-term relationships with students as experienced and trusted advisers (20). Medical students and residents have a tendency to join their educators who have taken on role models and to bring themselves closer to their educators in performance, appearances, and beliefs, and replicate their manners (19).

Social accountability of medical education programs requires all medical education and health policies to be made with the active participation of the community. Based on the suggestions of the specialized team of accountability in medical education, this will be achieved by establishing a need assessment system in the community, and through the design and implementation of longitudinal and field studies and finding the root causes of failure to meet these needs and community expectations. This method of determining community needs has been emphasized in numerous studies (21-24).

Also, medical sciences graduates are valuable resources to identify perceived educational gaps after their graduation and with the commencement of their professional life in the community. Recognizing the needs of the community is, of course, a continuous process. Data on these needs may be collected using different research approaches by using var- ious tools and collecting data from various sources, including health care recipients and providers or medical specialists. Community needs are finally identified by aggregating these data (21-25). To deepen the need-assessment process, the specialized team of accountability in medical education has recommended that the need-assessment studies be directed towards futurology, so that their results can be used in health system policymaking and training programs. Following the need assessment, it is necessary to explain and define the components, characteristics, and indicators of accountable education at all levels and dimensions of accountability to the community (26).

Another way to take advantage of the scientific ability of researchers in the field accountability in medical education is to guide the research and innovation activities of the university in line with responding to the needs of the community. Such activities, in addition to producing technology in the health system, can be effective in providing the necessary evidence for health decision-making (27-31).

Reducing the gap between the theoretical and practical education is another accountable instance of accountability in medical education (32). Efforts to make the medical education environment more like the real environment of providing health services is an effective measure that can be realized in many ways and has been emphasized in numerous studies (33-35).

The specialized team of accountability in medical education considered further empowering of universities to design and implement educational programs and determine the necessary conditions for student recruitment, essential for accountability of medical education to the needs of the community. Studies have shown that the authority of the medical universities is very limited in determining the criteria for student recruitment due to the centralized policies of student recruitment at the moment. In the terms of changing the content of curriculums, according to the prompted policies of Ministry of Health, changing the content of curriculums consists only up to $20 \%$ of the content of the curriculum.

Professional practice and commitment is the basis of accountability in medical education. Therefore, by improving the quality of education and assessment of medical ethics, principles of professionalism, and professional relations and commitment, we can ensure the achievement of social accountability in medical education. Dharamsi et al acknowledged that the use of specific methods in the interpretation of social responsibility could, on the one hand, increase social responsibility and, on the other, create limitations on its realization during the course of medical education and the practice of physicians in the future. The position of a physician in the community is closely associated with the creation of a sense of ethics of accountability in accepting professional features and the capacity to play this role in the community (36). Nonetheless, many scholars have identified professionalism as a complex and multidimensional social structure (37-40), which is important in the dimensions and characteristics of the structure, geographical location, and cultural considerations $(37,41)$. The teaching of medical ethics focuses on the formation of pro- 
fessionalism as a lifelong commitment to observing professionalism principles in the education, research, and provision of patient care services (42).

Based on the suggestions of the specialized team of accountability in medical education, provision of an appropriate policy package for guiding medical education programs for social accountability is important to facilitate advancement of accountability in medical education goals. The use of management models and upstream policy packages for conducting medical education programs is a common practice used in many countries and in various fields (43-45). Considering the coverage of the medical education programs for social accountability by the reform and innovation plan in medical education, the specialized team of accountability in medical education has recommended implementation, precise monitoring, and institutionalization of the reform package as a policy package before the medical science to realize accountability in medical education.

Educational programs at the national and academic levels have to pay special attention to empowerment-based education and to actively and continuously move towards the building of the community's needed capabilities. To this end, it is necessary to first collect the required capabilities of the graduates and develop a curriculum and determine the content, methods, educational arenas, and learner assessment methods based on them. Obviously, the evaluation of faculty members, in-service training, and educational management and leadership should also be in accordance with them and to realize the desired capabilities.

Caverzagie et al acknowledged that as the medical education systems are strongly determined to prepare future physicians to respond more effectively to the needs of patients and communities, competency-based medical education (CBME) can be a useful solution to align medical education with these social expectations (46). On the other hand, Hawkins et al (2015) also believe that despite the benefits of CBME, several concerns and challenges have been raised regarding the implementation of this model, including administrative requirements, the need for school development plans, the lack of a flexible model for curriculums, and instability in conditions and definitions. In addition, there are concerns about assessment approaches, the impossibility of a good assessment of some competencies, and the ambiguity about the quality of the needs assessment, and the extent to which the CBME framework covers emphasized competencies (47).

In education of medical students, along with theoretical and practical teaching of professional tasks, it is necessary to pay attention to strengthening the emotional field and achievements of this area such as attitude to understand and value the community health needs and to create a sense of commitment in learners towards social, economic, and cultural accountability. Several studies, while acknowledging the complexities of the effect of education on the emotional area, emphasize the necessity of targeting emotional changes as teaching-learning achievements (48-50).

The specialized team of accountability in medical education recommended that all academic institutions consider the main values of social accountability of education, namely equity, access, relevance, cost-effectiveness, and community participation (51-56).

Attention should be paid to the cost-effectiveness, flexibility, and local requirements in developing medical education indicators $(24,57-62)$.

Balance should be maintained in the training of human resources based on the evidence-based needs of the health system at all primary, secondary, and tertiary levels (63, 64).

Establishing an educational accreditation model and reviewing accreditation standards based on social accountability can be an effective step to strengthen accountability toward community needs (65-69). In a study of clinical learning environments, ACGME focused on improving quality to address inequalities in health care and aimed to make faculty members and medical assistants consider the interpersonal differences in the diverse populations of patients who they serve and respond to them in the form of designing quality improvement activities. They provided a framework for integrating quality improving programs and the principles of equity in medical education to meet the expectations of ACGME. In this regard, they presented a 4stage framework, along with strategies and tools for establishing equity in clinical education programs, and introduced quality improvement approaches to address equityrelated challenges in education (16).

Social accountability as a crucial component of transformative education necessitates increasing attention to the issues of governance, responsive curricula, educator preparedness, and appropriate student recruitment and selection. The need for a focus on addressing health inequalities and the delivery of effective, affordable, people-centered health care will be even more important in the event of a crisis in health care systems. In the meantime, socially accountable medical education program can make a significant contribution. Developing social accountability within medical education requires intentional and effective partnering with diverse internal and external stakeholders.

Social accountability is defined as the responsibility of medical schools to orientate their teaching, research, and service to meet the health and social needs of the communities that they serve.

Medical leadership requires commitment to implement social accountability frameworks for implementing effective decision-making processes, such as the revision of the medical school's strategic direction and the allocation of limited resources to address important, emerging medical education issues and challenges.

\section{Conclusion}

The 20-clause statement of this conference proposed social accountability as the main responsibility of universities of medical sciences as trustees of community health. To enact such an important task, strategies have been provided within the provisions of the statement for implementing, improving the quality, and ensuring implementation of the objectives of accountable and equitable education. Given the inadequate familiarity of stakeholders and those involved in medical education with the issue of accountability and how it is realized, and absence of a common lan- 
guage and appropriate attitude in this respect, changing organizational culture is the first required step. This can be realized through conferences and consensus of experts' views and spreading those views in all sections of medical education. The establishment of a permanent accountable and equitable medical education secretariat as an orderly institution can be a step toward acculturation and continuation of objectives and accountable educational programs in Iranian universities of medical sciences.

\section{Conflict of Interests}

The authors declare that they have no competing interests.

\section{References}

1. Weinstein DF, Thibault GE. Illuminating Graduate Medical Education Outcomes in Order to Improve Them. Acad Med. 2018;93(7):975-8.

2. Boelen C, Woollard B. Social accountability and accreditation: a new frontier for educational institutions. Med Educ. 2009(43):887-94.

3. Gohari M, Tabibi SJ, Nasiripour A, Mahboubi M. Seven Dimensions Of Accountability In Iran's Teaching Hospitals: A National Study. Payavard Salamat. 2012;6(4):255-64.

4. Akbari-Farmad S, Ahmady S, Hoseini MA. Exploring Faculty Members' Perceptions about Socially Accountable Medical Education Challenges: A Qualitative Content Analysis. Strides Dev Med Educ. 2016;13(1):1-9.

5. Dehghani M, Azizi F, Haghdoost A, Nakhaee N, Khazaeli P, Ravangard Z. Situation Analysis of Social Accountability Medical Education in University of Medical Sciences and Innovative Point of View of Clinical Faculty Members towards its Promotion Using Strengths, Weaknesses, Opportunities, and Threats (SWOT) Analysis Model. Strides Dev Med Educ. 2014;10:403-12.

6. Yamani N, Fakhari M. Social Accountability of Medical Education Curriculum: Barriers and Implications. Iran $\mathrm{J}$ Med Educ. 2014;13(12):1082-98

7. Schofield A, Bourgeois D. Socially responsible medical education: innovations and challenges in a minority setting. Med Educ. 2010;44(3):263-71.

8. Boelen C, Heck JE, Organization WH. Defining and measuring the social accountability of medical schools. Geneva: World Health Organization; 1995.

9. Steinbrook R. Private health care in Canada. N Engl J Med. 2006;354(16):1661-4.

10. Wynia MK. The short history and tenuous future of medical professionalism: the erosion of medicine's social contract. Perspect Biol Med. 2008;51(4):565-78.

11. Cruess RL, Cruess SR. Expectations and obligations: professionalism and medicine's social contract with society. Perspect Biol Med. 2008;51(4):579-98.

12. Verma S. Honouring the social contract:Medical schools take social responsibility seriously. University of Toronto Bulletin. November 14, 2005. http://www.afmc.ca/pdf/2005_social_contract.pdf. Accessed May 14, 2011.

13. Geyman JP. Privatization of medicare: Toward disentitlement and betrayal of a social contract. Int J Health Serv. 2004;34(4):573-94.

14. Dharamsi S, Pratt DD, MacEntee MI. How dentists account for social responsibility: economic imperatives and professional obligations. J Dent Educ. 2007;71(12):1583-92.

15. Drees S, Peters H. ASPIRE-to-excellence academy. Educ Med. 2016;17(3):115-8.

16. Aysola J, Myers JS. Integrating training in quality improvement and health equity in graduate medical education: two curricula for the price of one. Acad Med. 2018;93(1):31-4.

17. Hosny S, Ghaly M, Boelen C. Is our medical school socially accountable? The case of Faculty of Medicine, Suez Canal University. Med Teach. 2015;37(sup1):S47-S55.

18. Wang HH, Wang JJ, Wong S, Wong M, Mercer SW, Griffiths SM. The development of urban community health centres for strengthening primary care in China: a systematic literature review. Br Med Bullet. 2015;116(1):139-53.

19. Cruess RL, Cruess SR, Boudreau JD, Snell L, Steinert Y. A schematic representation of the professional identity formation and socialization of medical students and residents: a guide for medical educators. Acad Med. 2015;90(6):718-25.

20. Sambunjak D, Straus SE, Marušić A. Mentoring in academic medicine: a systematic review. JAMA. 2006;296(9):1103-15.

21. Strasser R, Worley P, Cristobal F, Marsh DC, Berry S, Strasser S, et al. Putting communities in the driver's seat: the realities of communityengaged medical education. Acad Med. 2015;90(11):1466-70.

22. Alyass A, Turcotte M, Meyre D. From big data analysis to personalized medicine for all: challenges and opportunities. BMC Med Genom. 2015;8(1):33.

23. Rowntree D. Assessing students: How shall we know them? Routledge; 2015.

24. Posavac EJ. Program evaluation: Methods and case studies: Routledge; 2015.

25. Bae S. Redesigning systems of school accountability: A multiple measures approach to accountability and support. Educ Policy Anal Arch. 2018;26:8.

26. Vanblaere B, Devos G. Relating school leadership to perceived professional learning community characteristics: A multilevel analysis. Teach Teach Educ. 2016;57:26-38.

27. Frieden TR. Evidence for health decision making-beyond randomized, controlled trials. N Engl J Med. 2017;377(5):465-75.

28. Lewin S, Glenton C, Munthe-Kaas H, Carlsen B, Colvin CJ, Gülmezoglu M, et al. Using qualitative evidence in decision making for health and social interventions: an approach to assess confidence in findings from qualitative evidence syntheses (GRADE-CERQual). PLoS Med. 2015;12(10):e1001895.

29. Stacey D, Légaré F, Lewis K, Barry MJ, Bennett CL, Eden KB, et al. Decision aids for people facing health treatment or screening decisions. Cochrane database Syst Rev. 2017(4):295.

30. George AS, Mehra V, Scott K, Sriram V. Community participation in health systems research: a systematic review assessing the state of research, the nature of interventions involved and the features of engagement with communities. PLoS One. 2015;10(10):e0141091.

31. Bowling A. Research methods in health: investigating health and health services: McGraw-Hill Education (UK); 2014.

32. Doukas DJ, Kirch DG, Brigham TP, Barzansky BM, Wear S, Carrese JA, et al. Transforming educational accountability in medical ethics and humanities education toward professionalism. Acad Med. 2015;90(6):738-43.

33. Wald HS, Anthony D, Hutchinson TA, Liben S, Smilovitch M, Donato AA. Professional identity formation in medical education for humanistic, resilient physicians: pedagogic strategies for bridging theory to practice. Acad Med. 2015;90(6):753-60.

34. Manners RA. Professional dominance: The social structure of medical care: Routledge; 2017.

35. Mirowsky J. Education, social status, and health: Routledge; 2017.

36. Dharamsi S, Ho A, Spadafora SM, Woollard R. The physician as health advocate: translating the quest for social responsibility into medical education and practice. Acad Med. 2011;86(9):1108-13.

37. Cruess SR, Cruess RL, Steinert Y. Teaching professionalism across cultural and national borders: lessons learned from an AMEE workshop. Med teach. 2010;32(5):371-4.

38. Stern DT. Measuring medical professionalism: Oxford University Press; 2006.

39. Martimianakis MA, Maniate JM, Hodges BD. Sociological interpretations of professionalism. Med Educ. 2009;43(9):829-37.

40. Ho MJ, Yu KH, Hirsh D, Huang TS, Yang PC. Does one size fit all? Building a framework for medical professionalism. Acad Med. 2011;86(11):1407-14.

41. Chandratilake M, McAleer S, Gibson J. Cultural similarities and differences in medical professionalism: a multi-region study. Med Educ. 2012;46(3):257-66.

42. Carrese JA, Malek J, Watson K, Lehmann LS, Green MJ, McCullough LB, et al. The essential role of medical ethics education in achieving professionalism: the Romanell Report. Acad Med. 2015;90(6):744-52.

43. Bowen H. Investment in learning: The individual and social value of American higher education: Routledge; 2018.

44. Huang TT, Cawley JH, Ashe M, Costa SA, Frerichs LM, Zwicker L, et al. Mobilisation of public support for policy actions to prevent obesity. Lancet. 2015;385(9985):2422-31.

45. Acharya B, Maru D, Schwarz R, Citrin D, Tenpa J, Hirachan S, et al. Partnerships in mental healthcare service delivery in low-resource 
settings: developing an innovative network in rural Nepal. Glob Health. 2017;13(1):2.

46. Caverzagie KJ, Nousiainen MT, Ferguson PC, ten Cate O, Ross S, Harris KA, et al. Overarching challenges to the implementation of competency-based medical education. Med Teach. 2017;39(6):588-93.

47. Hawkins RE, Welcher CM, Holmboe ES, Kirk LM, Norcini JJ, Simons KB, et al. Implementation of competency-based medical education: are we addressing the concerns and challenges? Med Educ. 2015;49(11):1086-102.

48. Yakovleva N. Corporate social responsibility in the mining industries: Routledge; 2017.

49. Pálsdóttir B, Barry J, Bruno A, Barr H, Clithero A, Cobb N, et al. Training for impact: the socio-economic impact of a fit for purpose health workforce on communities. Hum Resour Health. 2016;14(1):49.

50. Zimmerman EB, Woolf SH, Haley A. Understanding the relationship between education and health: a review of the evidence and an examination of community perspectives. Population health: behavioral and social science insights Rockville (MD): Agency for Health-care Research and Quality. 2015:347-84.

51. Whitty JA, Littlejohns P. Social values and health priority setting in Australia: an analysis applied to the context of health technology assessment. Health Policy. 2015;119(2):127-36.

52. Javanparast S, Windle A, Freeman T, Baum F. Community health worker programs to improve healthcare access and equity: are they only relevant to low-and middle-income countries? Int J Health Policy Manag. 2018;7(10):943-954.

53. Rabeea'h WA, Hendry M, Booth A, Carter B, Charles JM, Craine N, et al. Intervention Now to Eliminate Repeat Unintended Pregnancy in Teenagers (INTERUPT): a systematic review of intervention effectiveness and cost-effectiveness, and qualitative and realist synthesis of implementation factors and user engagement. BMC Med. 2017;15(1):155.

54. Mostafavi H, Rashidian A, Arab M, Mahdavi MRV, Ashtarian K. Health Priority Setting in Iran: Evaluating Against the Social Values Framework. Glob J Health Sci. 2016;8(10):212.

55. Green-Thompson LP, McInerney P, Woollard B. The social accountability of doctors: a relationship based framework for understanding emergent community concepts of caring. BMC Health Serv Res. 2017;17(1):269.

56. Barasa EW, Molyneux S, English M, Cleary S. Setting healthcare priorities at the macro and meso levels: a framework for evaluation. Int J Health Policy Manag. 2015;4(11):719.

57. Meara JG, Leather AJ, Hagander L, Alkire BC, Alonso N, Ameh EA, et al. Global Surgery 2030: evidence and solutions for achieving health, welfare, and economic development. Lancet. 2015;386(9993):569-624.

58. Prince M, Comas-Herrera A, Knapp M, Guerchet M, Karagiannidou M. World Alzheimer report 2016: improving healthcare for people living with dementia: coverage, quality and costs now and in the future. London: Alzheimer's Disease International, 2016.

59. Pecora P, Whittaker J, Barth R, Maluccio AN, DePanfilis D, Plotnick RD. The child welfare challenge: Policy, practice, and research: Routledge; 2017.

60. Sanders GD, Neumann PJ, Basu A, Brock DW, Feeny D, Krahn M, et al. Recommendations for conduct, methodological practices, and reporting of cost-effectiveness analyses: second panel on costeffectiveness in health and medicine. JAMA. 2016;316(10):1093-103.

61. Brown MM. Transitions of Care. Chronic Illness Care: Springer; 2018. p. 369-73.

62. Alley DE, Asomugha CN, Conway PH, Sanghavi DM. Accountable health communities-addressing social needs through Medicare and Medicaid. N Engl J Med. 2016;374(1):8-11.

63. Organization WH. Global strategy on human resources for health: workforce 2030. 2016.

64. Johnson S, Robertson I, Cooper CL. Improving Well-Being: Building a Healthy Workplace. WELL-BEING: Springer; 2018. p. 125-36.

65. Dent J, Harden RM, Hunt D. A practical guide for medical teachers: Elsevier Health Sciences; 2017.

66. Edgar L, Roberts S, Yaghmour NA, Hunderfund AL, Hamstra SJ, Conforti L, et al. Competency crosswalk: a multispecialty review of the Accreditation Council for Graduate Medical Education milestones across four competency domains. Acad Med.2018;93(7):1035-41.

67. Eaton JS. An Overview of US Accreditation. Revised November 2015. Council for Higher Education Accreditation. 2015.

68. Blouin D, Tekian A. Accreditation of medical education programs: moving from student outcomes to continuous quality improvement measures. Acad Med.2018;93(3):377-83.

69. Pavlakis A, Kelley C. Accreditation in the professions: Implications for educational leadership preparation programs. J Res Leadersh Educ. 2016;11(1):68-90. 